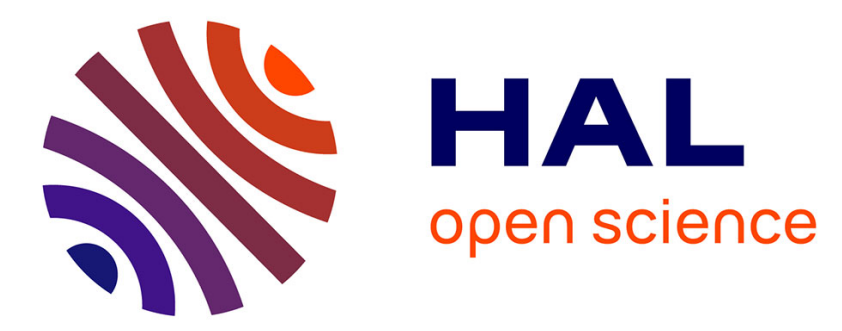

\title{
Managing Standardization in eGovernment: A Coordination Theory based Analysis Framework
}

\author{
Dian Balta, Helmut Krcmar
}

\section{To cite this version:}

Dian Balta, Helmut Krcmar. Managing Standardization in eGovernment: A Coordination Theory based Analysis Framework. 17th International Conference on Electronic Government (EGOV), Sep 2018, Krems, Austria. pp.60-72, 10.1007/978-3-319-98690-6_6 . hal-01961534

\author{
HAL Id: hal-01961534 \\ https://hal.inria.fr/hal-01961534
}

Submitted on 20 Dec 2018

HAL is a multi-disciplinary open access archive for the deposit and dissemination of scientific research documents, whether they are published or not. The documents may come from teaching and research institutions in France or abroad, or from public or private research centers.
L'archive ouverte pluridisciplinaire HAL, est destinée au dépôt et à la diffusion de documents scientifiques de niveau recherche, publiés ou non, émanant des établissements d'enseignement et de recherche français ou étrangers, des laboratoires publics ou privés. 


\title{
Managing Standardization in eGovernment: A Coordination Theory based Analysis Framework
}

\author{
Dian Balta ${ }^{1}$ and Helmut Krcmar ${ }^{2}$ \\ ${ }^{1}$ fortiss GmbH, Guerickestr. 25, 80805 Muenchen, Germany \\ baltalfortiss.org \\ ${ }^{2}$ Informatics 17 - Chair for Information Systems, Technical University of Munich, \\ Boltzmannstr. 3, 85748 Garching, Germany
}

\begin{abstract}
Standardization plays an important role for a smooth organizational, semantic, technical and legal interoperation of eGovernment services. Still, standardization struggles with the complexity of administrative procedures that have to be supported and provided online. Managing this complexity poses a crucial challenge for an efficient and effective eGovernment. Different management frameworks have been developed, but the progress of standardization in practice is still perceived as insufficient. To address the challenge of standardization management in eGovernment, we propose a coordination theory based framework for analysis. It consists of three coordination modes distinguished based on their mechanisms and relevant context dimensions. In our research approach, we interpret a single case study of a standardization project in Germany where artefacts were developed from a pragmatism perspective. We discuss our findings and conclude on implications for research and practice.
\end{abstract}

Keywords: Standardization, Coordination, Management.

\section{Introduction}

Standards play an important role in effective and efficient service provision in government [1-3]. For instance, standards are applied to harmonize business processes [4] and to efficiently share information [5] at the right time with the right people and in the right quality [6] by enabling the interconnectivity of the information systems that underlie the provision of services to citizens and companies [7]. Choosing a suitable standardization approach and coordination of the corresponding process $[8,9]$ based on the context and expected benefits of an eGovernment project $[10,11]$ are a prerequisite for its success $[1,12,13]$.

Coordination of standardization faces a number of challenges in the government domain due to the adherent complexity of administrative procedures [2, 14, 15]. Research on standardization in organizations [16] and information systems management [17] has emphasized measures to counter complexity challenges (e.g. [12], [18]), but the measures' applicability in a government context is limited by differences between private organizations and government bodies [19],[20]. In particular, little is known of what should be coordinated in order to manage the dependencies between actors in- 
volved in standardization of administrative procedures. Extant research addresses predominantly how and why to coordinate[21], e.g. how to coordinate applying particular information system architectures (e.g. [22], [23],[24]), how coordination evolves in public administrations (e.g. [25]) and why coordination is crucial for an eGovernment driven transformation of administrative procedures (e.g. [26]).

Our research goal is to develop a coordination theory based framework for analysis and effective standardization of administrative procedures in eGovernment that comprises three modes of coordination. Each mode is described by a set of applicable mechanisms and is distinguished from other modes based on a set of dimensions that allow for justifying its application in a given situation. To develop the framework, we conduct a qualitative study on coordination by interpreting artefacts developed in a standardization project. To describe the applicability of the framework, we exemplify the insights gained in the project under study.

This paper is structured as follows. In the next chapter we describe the theoretical background of the paper. Next, we describe our research approach. In chapter four, we derive our coordination theory based framework. Next, we present an exemplary application of the framework. Finally, we discuss our results and conclude on implications for theory and practice.

\section{Theoretical Background}

\subsection{Standardization}

We define a standard as "a uniform set of measures, agreements, conditions, or specifications between parties" [27]. The process of reaching a standard encompasses stabilizing and solidifying its definition and boundaries [12, 28], i. e. standardization represents "the activity of establishing and recording a limited set of solutions to actual or potential matching problems directed at benefits for the party or parties involved balancing their needs and intending and expecting that these solutions will be repeatedly or continuously used during a certain period by a substantial number of the parties for whom they are meant" [29].

Standardization can be divided into five general levels of solutions for the parties involved [30, 31]. First, reference models are defined on the first level, followed by a set of functions and technologies on the second level. The third level is represented by a functional profile that determines the user group's requirements. The fourth level is described by a system profile that determines the requirements of specific classes of users. Finally, a specific application implementation is represents the fifth level of standardization.

Since standardization involves information systems, process and organizations and different federal layers [2, 32, 33], standards at different levels as solutions for managing information and underlying systems are a necessity for improving the maturity of digitalized government services [34]. Although this necessity represents one of the drivers for an increased attention to standardization in government $[8,35]$, standardization in eGovernment practice is challenging. In particular, standardization is challenged by the complexity of government procedures [14], [2] and is often ineffective 
in practice [36], [37]. Various approaches to information management that are tailored to the context of government bodies through standardization have been developed in response [38],[39]. For example, frameworks like SAGA in Germany [40], with its focus on software specifications and development methods in the context of government bodies, and the European Interoperability Framework [41] have been proposed to management practice. Consequently, addressing standardization at different federal layers and at different levels would benefit from an effective coordination.

\subsection{Coordination}

Coordination is seen as a central concept regarding the design of organizations (e.g., [42], [43], [44] ) and work (e.g. [45]). It represents a topic of study at different levels, e.g. individual, community, and in multiple disciplines [46], including IS, management and e-government. Prior research on information systems management and organization design has focused primarily on assessing the efficacy of various coordination mechanisms [47] as well as on the causality of their outcomes [44]. For instance, it has addressed integrative conditions of coordination such as accountability, predictability, and common understanding [45], the applicability of different coordination modes in the context of knowledge-intensive work [48-50], mechanisms targeting IT use and capabilities that are based on steering committees and communication policies $[51,52]$ as well as sharing of knowledge and spanning of systemic and organizational boundaries [53-55].

With regard to extant literature and the numerous perspectives on coordination [4446, 56], this paper addresses coordination as a means for "managing dependencies between activities" [46]. Since coordination takes place between individuals [49, 57], we use the term coordination of administrative procedures to denote the management of dependencies between activities involving persons and the resources (e.g. information, knowledge) they exchange in regarding an eGovernment administrative procedure. Further, coordination is exerted through different mechanisms that can be predefined or emerge based on the context there are applied in [57-59].

\section{Research Approach}

The research described in this paper is conducted as a qualitative study of coordination in information systems [60,61], epistemologically rooted in two paradigms: interpretation [62],[63] as well as pragmatism [64], [65]. We choose this approach in accordance with [65], [66] for two reasons. On the one hand, the authors were involved in dialogical action during the project Federal Information Management (FIM) under study in their role as scientific consultants [67]. This allowed for an in-depth study of a single case. On the other hand, we aim at the development of a theory based artifact combining interpretation of work [63] well as practical inquiry [65]. 


\subsection{Case Background}

In Germany, administrative procedures are situated on federal, state and community level and, with regard to administrative traditions [33], can be described as quiet heterogeneous between the levels. They often differ in their design and execution in public administrations situated at the same level, e.g. two communities in the same state could exchange information with involved actors during a procedure in a totally different way depending on public administration size or the information technology landscape of the community.

In an effort to manage the complexity of numerous and heterogeneous administrative procedures, the federal and state public administrations in Germany started in 2012 the project FIM to standardize procedures at all federal layers on a reference model level and is currently applied in the design of an interoperable government service platform. Each administrative procedure was described as a combination of a service, an underlying process to execute it and a set of forms for input or output data in the process. Since the project had the management attention at chief information officers' level of the German Federation as well as of all German States, we were able to interact intensively with experts and practitioners at all federal levels.

\subsection{Data Collection and Analysis}

Empirical data collection and analysis took place in several phases (cf. Fig. 1). First, potentially relevant standardization initiatives in Germany were identified (phase I). We conducted expert interviews during project meetings and eGovernment practitioner conferences in Germany as well as an analysis of documents regarding standardization initiatives presented in German public meetings, conferences and congresses. Based on our findings, we identified addressees for a preliminary survey of relevant initiatives. The survey was conducted by e-mail or phone with employees in IT management positions at federal or state public administrations and resulted in 40 potentially relevant initiatives ${ }^{1}$.

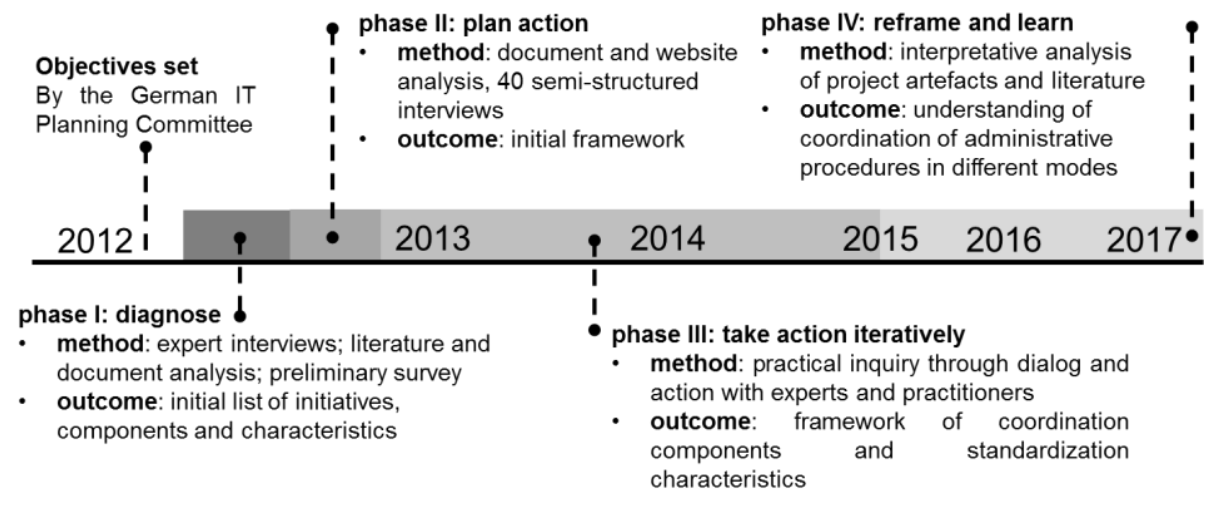

Fig. 1. Research phases of data collection and analysis

${ }^{1} \mathrm{cf}$. http://fim.yourresearchportal.com/ for the initial data set applied in our research. 
In a second step, data was obtained through the analysis of websites and publications regarding each initiative as well as by interviewing public administration employees based on the survey (phase II). Prior to each interview, we sent a scheme for analysis of components and characteristics of standardization aimed at by each initiative that we developed. Consequently, we were able to conduct a total of 40 semi-structured in-depth interviews in person or per telephone, with duration between 15 and 45 minutes per interview. The interview data was used to complement the information on the initiatives obtained during the first step. Eventually, we identified 30 relevant initiatives in German public administration and to derive our initial framework.

Next, we developed coordination components and standardization characteristics as a framework for developing reference models for administrative procedures, documented it and discussed its application with experts in workshops, focus groups or individual interviews (phase III). Based on this framework, we created text documents, presentations as well as workshop protocols in dialogue and action together with experts and practitioners [67] regarding the application and evaluation of our framework. This "practical inquiry" [65] allowed us to mix and improve both practitioner's and researcher's experience on coordination of administrative procedures through the mechanism of standardization. Consequently, we were able to provide for a satisfactory remedy to a real problem [67] and the framework as an artefact represented "constructive knowledge" [65] towards an effective coordination of complex administrative procedures.

Finally, we studied all project artefacts and literature in an interpretative phase (phase IV) through an argumentative-deductive analysis [68]. Thus, we incrementally adjusted our interpretation [69], [63] by reframing our artefacts taking a coordination theory perspective. Thus, we were able to learn and enhance our understanding [65] and to contribute to theory towards effective coordination through standardization of complex administrative procedures considering different coordination modes.

\section{A Coordination Theory based Framework for Standardization Management}

Three modes of coordination can be distinguished [48, 49], [70]: two modes of explicit coordination referred to as planning and feedback as well as a third mode, complementary to the previous two modes, referred to as tacit coordination $[48,49]$ (cf. Table 1). The first mode, explicit coordination by planning, involves a designer, who partitions activities into capsuled modules and builds interfaces between the modules [48, 49, 71]. Applicable planning mechanisms involve pre-established plans, schedules, forecasts, formalized rules, policies etc. For example, consider the electronic data interchange protocol as a mechanism of coordination by planning. It involves a number of actors (companies with their employees) that accomplish tasks in their own modules and exchange information based on the protocol as an interface between the modules.

The second mode, explicit coordination by feedback, represents "mutual adjustments" between the individuals that take place "upon new information" [43, 72]. Ap- 
plicable mechanisms in this mode involve ongoing communication: an on-demand face-to-face (or virtual) personal or group communication takes place. For example, a scheduled or unscheduled group meeting takes place in order to cope with challenges resulting from new information relevant for the task at hand. The actors that take part in the meeting adjust their knowledge by active communication.

The third mode, tacit coordination, involves the notion that coordination takes place in a tacit manner. Mechanisms in this mode build or leverage shared (tacit or explicit) knowledge [48, 49, 73]. Sharing knowledge is accomplished through boundary objects [45, 49, 74] and can span across organizational [53-55]. For example, a team can be staffed with an experienced member from another team who is able to transfer context based knowledge into the task at hand in the new team. An experienced team member can introduce a boundary object such as a software codebase [50] and other team members can coordinate by adapting their own tasks according to the codebase without the need of a particular coding protocol or an intense ongoing communication. Consequently, tacit coordination takes place as an indirect communication between the actors while the task at hand is being implemented [49]. Moreover, it helps to share task specific knowledge between contexts [48].

Table 1. A coordination theory based framework for standardization management

\begin{tabular}{|c|c|c|c|}
\hline & $\begin{array}{l}\text { Planning mode } \\
\text { (explicit) }\end{array}$ & node (explicit) & $\begin{array}{l}\text { Knowledge exchange } \\
\text { mode (tacit) }\end{array}$ \\
\hline $\begin{array}{l}\text { General } \\
\text { mechanism }\end{array}$ & $\begin{array}{l}\text { partitioning of } \\
\text { tasks into modules } \\
\text { and defining inter- } \\
\text { faces }\end{array}$ & $\begin{array}{l}\text { establishment of an on- } \\
\text { demand, face-to-face (or } \\
\text { virtual) ongoing communi- } \\
\text { cation }\end{array}$ & $\begin{array}{l}\text { exchange and adaption of } \\
\text { boundary objects, transfer } \\
\text { of resources }\end{array}$ \\
\hline $\begin{array}{l}\text { Common } \\
\text { ground be- } \\
\text { tween actors }\end{array}$ & $\begin{array}{l}\text { minimal, constant } \\
\text { level }\end{array}$ & constant updates & $\begin{array}{l}\text { knowledge transfer and } \\
\text { updates by adaptation to } \\
\text { context }\end{array}$ \\
\hline $\begin{array}{l}\text { Communica- } \\
\text { tion }\end{array}$ & $\begin{array}{l}\text { impersonal, "one- } \\
\text { time" communica- } \\
\text { tion, modules and } \\
\text { interfaces }\end{array}$ & $\begin{array}{l}\text { personal or in group ongo- } \\
\text { ing communication }\end{array}$ & $\begin{array}{l}\text { different possible ways to } \\
\text { communicate, but explicit } \\
\text { communication is not a } \\
\text { prerequisite }\end{array}$ \\
\hline Environment & $\begin{array}{l}\text { stable, pre- } \\
\text { established tasks } \\
\text { and responsibili- } \\
\text { ties }\end{array}$ & $\begin{array}{l}\text { dynamic, innovative tasks } \\
\text { under volatile conditions }\end{array}$ & $\begin{array}{l}\text { dynamic, innovative tasks } \\
\text { under volatile conditions }\end{array}$ \\
\hline $\begin{array}{l}\text { Interdepen- } \\
\text { dency type }\end{array}$ & $\begin{array}{l}\text { pooled or sequen- } \\
\text { tial interdepend- } \\
\text { ency }\end{array}$ & reciprocal interdependency & $\begin{array}{l}\text { reciprocal or team interde- } \\
\text { pendency }\end{array}$ \\
\hline Example & $\begin{array}{l}\text { Public administra- } \\
\text { tions in the EU } \\
\text { using the eIDAS } \\
\text { message format }\end{array}$ & $\begin{array}{l}\text { a telephone call or a meet- } \\
\text { ing, an online video con- } \\
\text { ference }\end{array}$ & $\begin{array}{l}\text { a software codebase }[50] \text {, } \\
\text { team staffing with an expe- } \\
\text { rienced member from an- } \\
\text { other team [48] }\end{array}$ \\
\hline
\end{tabular}


For each of the three modes, the management of dependencies between activities involves an analysis of the situation of coordination [46]. The situation comprises an understanding of which activities and dependencies should be coordinated [46]. It can be described along the following dimensions: (i) the common ground of the actors involved, (ii) the applicable means of communication, (iii) the aspects of the environment where the coordination takes place as well as (iv) the type of interdependencies to be considered $[46,75]$. We refer to the dimensions of the situation of coordination to emphasize the differences between the modes as follows (cf. Table 1).

The first dimension common ground is denoted as knowledge that is or will be shared in order to allow for reciprocal predictability of action [49, 73, 76]. Coordination by planning involves a minimal level of common ground that is constant, i.e. the actors share knowledge to a limited extent and rarely update it (e.g. an information exchange protocol). In contrast, feedback and tacit coordination involve constantly updates of the knowledge shared by individuals: feedback, trough ongoing communication, and, regarding tacit coordination, through knowledge adaptation to context.

The second dimension - communication - considers how the actors involved exchange information upon coordinating task accomplishment [77], [42]. Coordination by planning and feedback represent two poles regarding this dimension. Since planning involves upfront definition of modules and interfaces (as a means to exchange resources such as knowledge between the modules), the communication is impersonal and takes place on an irregular pace (e.g. at the beginning of the task accomplishment). On the contrary, coordination by feedback comprises ongoing personal or group communication with no pre-established protocols to follow. Similar to feedback, tacit coordination might involve personal communication or any pre-established protocols. Still in this mode, communication is not ongoing or even not a prerequisite, since the common ground can be built without it through knowledge adaptation to context (e.g. shared source code base).

Environment, the third dimension of a situation of coordination, considers the contextual setting in which the tasks take place. Thus, it includes external factors that influence the actors and their activities. Basically, an environment can be dynamic or stable, i.e. (i) it accounts for innovative tasks that require novel common ground and do not rest upon pre-established plans or responsibilities or (ii) it accounts for common well-known tasks that can be accomplished based on pre-defined modules and interfaces. Feedback and tacit coordination account for mechanisms applicable to a more dynamic environment, while mechanisms of the planning mode suit a more stable environment.

The fourth dimension - interdependency type - addresses how each actor depends on the other actors during task accomplishment. Four dependency types can be distinguished: pooled, sequential, reciprocal and team interdependency [75, 78, 79]. Coordination by planning is suitable to interdependencies of the first and second type, i.e. one central actor (acting as a pool) coordinates the actions of other actors (according to pre-defined modules) or actors accomplish task in a sequence with interfaces between each actor (e.g. according to a predefine protocol). Feedback is suitable to the coordination of reciprocal dependencies between actors, i.e. exchange of resources relevant for task accomplishment takes place between all actors (e.g. a group meet- 
ing). Similar to feedback, tacit coordination is suitable to reciprocal dependencies. Moreover, it is suitable to team interdependency, i.e. reciprocal differences exist and actors simultaneously collaborate towards task accomplishment.

Since tacit coordination is complementary to the both explicit coordination modes, in a particular situation of coordination a combination of the modes should be expected. Consequently, mechanisms applied in each mode should address the complementary function of the modes.

\section{Exemplary Application of the Framework}

We analyze the project FIM based on our framework (cf. Table 2) and emphasize a set of artefacts- targeted at an efficient and effective standardization using reference models of services, processes and forms-that resulted in the project. Hence, we aim at justifying each artefact according to its coverage of a particular mode of coordination.

Table 2. Analysis of the project FIM using our coordination theory based framework

\begin{tabular}{|c|c|c|c|}
\hline & $\begin{array}{l}\text { Planning mode (ex- } \\
\text { plicit) }\end{array}$ & Feedback mode (explicit) & $\begin{array}{l}\text { Knowledge exchange } \\
\text { mode (tacit) }\end{array}$ \\
\hline $\begin{array}{l}\text { Common } \\
\text { ground } \\
\text { between } \\
\text { actors }\end{array}$ & $\begin{array}{l}\text { Laws and predefined } \\
\text { application forms }\end{array}$ & $\begin{array}{l}\text { Newly established or up- } \\
\text { dated laws }\end{array}$ & $\begin{array}{l}\text { a common library of } \\
\text { models of form models, } \\
\text { processes and services }\end{array}$ \\
\hline $\begin{array}{l}\text { Communi- } \\
\text { cation }\end{array}$ & $\underline{\text { Editorial process }}$ & $\begin{array}{l}\text { Working groups consisting } \\
\text { of experts and service } \\
\text { personal }\end{array}$ & $\begin{array}{l}\text { Introduce model owner } \\
\text { to the design process }\end{array}$ \\
\hline $\begin{array}{l}\text { Environ- } \\
\text { ment }\end{array}$ & Laws that change rare & Laws that change each year & $\begin{array}{l}\text { Laws that change each } \\
\text { year }\end{array}$ \\
\hline $\begin{array}{l}\text { Interdepen- } \\
\text { dency type }\end{array}$ & Federal structure & $\begin{array}{l}\text { Working groups based on } \\
\text { specific topics }\end{array}$ & External consultants \\
\hline
\end{tabular}

We applied the dimensions and the modes to analyze what means of coordination should be provided. First, our analysis showed a need for action in terms of introducing an editorial process as a planning mode of communication. Since each standard for an administrative procedure represents a reference model and cannot be defined in great detail, the strictly predefined process allows for keeping the standardization effective and with a minimal effort [72]. Second, our analysis shows that the feedback mode is applicable to a newly established or updated laws, since a constant update of the knowledge inside working groups is required for an effective design of a reference model Third, we came to the conclusion that a common library of models of application forms, processes and services is required as a common ground. This library would allow for reusing elements without strictly limiting the standardization process, i. e. we suggest a suitable level of standard flexibility [13]. Fourth, we figured out that 
a new role is needed during the design process-referred to as model designer-that should transport existing artefact knowledge between different application domains and mediate the development of new or updated reference models.

\section{Discussion and conclusion}

Our research goal was to develop a coordination theory based framework for analysis and effective standardization of administrative procedures in eGovernment. We introduced a framework that consists of three coordination modes (planning, feedback and knowledge exchange) with corresponding coordination mechanisms. Additionally, we introduce four context dimensions (common ground between actors, communication, environment, interdependency type) that help to study and describe the situation of coordination in which each mode should be applied. The framework was derived based on a single case study and interpretation of the artefacts developed in it. To exemplify the applicability of the framework, we showed how the artefacts developed in the project under are matched to particular coordination modes. Thus, we showed how the framework allows for analyzing what to coordinate towards effective standardization.

Our analysis framework represents a theoretical contribution to eGovernment research and practice [80]. Future research can comprise a quantitative study of standardization performance. Additionally, the framework can be extended with prescriptive design guidelines for an effective and efficient standardization. Practitioners can apply our framework to analyze ongoing and planned standardization activities and to evaluate the feasibility of applied coordination mechanisms.

\section{References}

1. Hanseth, O., Bygstad, B.: Flexible generification: ICT standardization strategies and service innovation in health care. European Journal of Information Systems;24(6):645-63 (2015).

2. Janssen, M., Charalabidis, Y., Kuk, G., Cresswell T.: Guest Editors' Introduction: Egovernment Interoperability, Infrastructure and Architecture: State-of-the-art and Challenges. Journal of theoretical and applied electronic commerce research;6(1):I-VIII (2011).

3. Scholta, H., Balta, D., Wolf, P., Becker, J., Krcmar, H.: Standardization of Service Descriptions, Process Models and Forms in Public Administrations: Results from a Survey in Germany. Electronic Government and Electronic Participation, 245-52 (2015).

4. Becker, J., Algermissen, L., Falk, T.: Modernizing Processes in Public Administrations: Process Management in the Age of e-Government and New Public Management. SpringerVerlag, Berlin, Heidelberg (2012).

5. Scholl, H.J., Kubicek, H., Cimander, R., Klischewski, R.: Process integration, information sharing, and system interoperation in government: A comparative case analysis. Government Information Quarterly;29(3):313-23 (2012).

6. Radack, S.M.: More effective federal computer systems: The role of NIST and standards. Government Information Quarterly; 7:37-49 (1990). 
7. Borras, J.: International Technical Standards for e-Government. Electronic Journal of eGovernment ;2:75-80 (2004).

8. Charalabidis, Y., Lampathaki, F., Askounis, D.: A Comparative Analysis of National Interoperability Frameworks. 15th Americas Conference on Information Systems (2009).

9. Gionis, G., A., Schroth, C., Janner, T.: Advancing Interoperability for Agile CrossOrganisational Collaboration: A Rule-Based Approach. In: Charalabidis Y, editor. Interoperability in Digital Public Services and Administrations: Bridging E-Government and E-Business. USA: Information Science Reference; (2011).

10. Balta, D., Greger, V., Wolf, P., Krcmar, H.: Why Realization Mismatches Expectations of e-Government Project Benefits? Towards Benefit Realization Planning. In: Tambouris E. et al., editor. Electronic Government EGOV; Lecture Notes in Computer Science. Springer, Cham; p. 233-45 (2015).

11. Balta, D., Greger, V., Wolf, P., Krcmar, H.: E-government stakeholder analysis and management based on stakeholder interactions and resource dependencies. 48th Hawaii International Conference on System Sciences (2015).

12. Hanseth, O., Jacucci, E., Grisot, M., Aanestad, M.: Reflexive Standardization: Side Effects and Complexity in Standard Making. MIS Quarterly;30:563-81 (2006).

13. Hanseth, O., Monteiro, E., Hatling, M.. Developing Information Infrastructure: The Tension Between Standardization and Flexibility. Science, Technology \& Human Values; 21(4):407-26 (1996).

14. Bharosa, N., Lee, J., Janssen, M.: Challenges and obstacles in sharing and coordinating information during multi-agency disaster response: Propositions from field exercises. Inf Syst Front. 2009;12(1):49-65.

15. Janssen, M.: Sociopolitical Aspects of Interoperability and Enterprise Architecture in EGovernment. Social Science Computer Review (2011).

16. Brunsson, N., Rasche, A., Seidl, D.: The Dynamics of Standardization: Three Perspectives on Standards in Organization Studies. Organization Studies (2012).

17. Lyytinen, K., King, J., L.: Standard Making: A Critical Research Frontier for Information Systems Research. MIS Quarterly:405-11 (2006).

18. Markus, M.L., Steinfield, C.W., Wigand, R.T.: Industry-Wide Information Systems Standardization as Collective Action: The Case of the U.S. Residential Mortgage Industry. MIS Quarterly (2006).

19. Rainey, H.G., Ronquillo, J.C., Avellaneda, C.N.: Decision making in public organizations. Handbook of Decision Making (2010).

20. Jurisch, M.C.: IT - enabled Business Process Change in Private and in Public Sector Organizations. Technische Universität München (2014).

21. Faraj, S., Xiao, Y.: Coordination in Fast-Response Organizations. Management Science; 52(8):1155-69 (2006).

22. Hofmann, S., Beverungen, D., Räckers, M., Becker, J.: What makes local governments' online communications successful? Insights from a multi-method analysis of Facebook. Government Information Quarterly; 30(4):387-96 (2013).

23. Klischewski, R.: Architectures for tinkering? Contextual strategies towards interoperability in E-government. Journal of theoretical and applied electronic commerce research; 6(1):26-42 (2011).

24. Kuehn, A., Kaschewsky, M., Kappeler, A., Spichiger ,A., Riedl R.: Interoperability and information brokers in public safety: An approach toward seamless emergency communications. Journal of theoretical and applied electronic commerce research; 6(1):43-60 (2011).

25. Jacobson, D.D.: How and why network governance evolves: evidence from a public safety network. Electronic Markets;26(1):43-54 (2016). 
26. Gao, X., Song, Y., Zhu, X.: Integration and coordination: Advancing China's fragmented e-government to holistic governance. Government Information Quarterly; 30(2):173-81 (2013).

27. Spivak, S.M., Brenner F.C.: Standardization essentials: Principles and practice. CRC Press (2001).

28. David, P.A., Greenstein S.: The Economics of Compatibility Standards: an Introduction To Recent Research. Economics of Innovation and New Technology; I(1-2):3-41 (1990).

29. De Vries, H.J.: Standardization: A business approach to the role of national standardization organizations: Springer (1999).

30. Egyedi, T.M.: Shaping Standardization: A Study of Standards Processes and Standards Policies in the Field of Telematic Services. Delft: Delft University Press (1996).

31. Cargill, C.F.: Information technology standardization: theory, process, and organizations: Digital Press (1989).

32. Janssen, M., Snijders, B., Herkemij, F.: A Reference Architecture for Interoperable and Adaptive Processes. In: Charalabidis, Y., editor. Interoperability in Digital Public Services and Administrations: Bridging E-Government and E-Business. United States of America: Information Science Reference; p. 162-79 (2011).

33. Misuraca, G., Alfano, G., Viscusi, G.: Interoperability Challenges for ICT-enabled Governance: Towards a pan-European Conceptual Framework. Journal of theoretical and applied electronic commerce research;6(1):95-111 (2011).

34. Lam, W.: Barriers to e-government integration. Journal of Enterprise Information Management; 18(5):511-30 (2006).

35. Hellberg, A.-S., Grönlund, Å.: Conflicts in implementing interoperability: Reoperationalizing basic values. Government Information Quarterly; 30(2):154-62 (2013).

36. Blum, U.: Lessons from the Past: Public Standardization in the Spotlight. International Journal of IT Standards and Standardization Research; 3(1):1-20 (2005).

37. Scholl H.J., Klischewski, R.: E-Government Integration and Interoperability: Framing the Research Agenda. International Journal of Public Administration; 30(8-9):889-920 (2005).

38. Guijarro, L.: Interoperability frameworks and enterprise architectures in e-government initiatives in Europe and the United States. Government Information Quarterly; 24(1):89-101 (2007).

39. Büttner, F., Bartels, U., Hamann, L., Hofrichter, O., Kuhlmann, M., Gogolla, M.: Modeldriven standardization of public authority data interchange. Science of Computer Programming (2014).

40. Federal Government Commissioner for Information Technology: SAGA-Modul Grundlagen Version de.bund 5.1.0. In: Interior FM, editor. Berlin (2011).

41. European Commission: European Interoperability Framework (EIF) for European public services. European Commission E, editor. Brussels (2010).

42. Galbraith, J.R.: Organization design: An information processing view. Organizational Effectiveness Center and School; 21:21-6 (1977).

43. Thompson, J.D.: Organizations in action: Social science bases of administration. Transaction publishers (1967).

44. Williams, C.K., Karahanna, E.: Causal Explanation In The Coordinating Process: A Critical Realist Case Study Of Federated It Governance Structures. MIS Quarterly; 37(3) (2013).

45. Okhuysen, G.A., Bechky, B.A.: Coordination in Organizations: An Integrative Perspective. Academy of Management Annals; 3(1):463-502 (2009).

46. Malone, T.W., Crowston, K.: The interdisciplinary study of coordination. ACM Computing Surveys (CSUR); 26(1):87-119 (1994). 
47. Brown, C.V.: Horizontal Mechanisms under Differing IS Organization Contexts. MIS Quarterly; 23(3):421-54 (1999).

48. Srikanth, K., Puranam, P.: Integrating distributed work: comparing task design, communication, and tacit coordination mechanisms. Strategic Management Journal; 32(8):849-75 (2011).

49. Srikanth, K., Puranam, P.: The firm as a coordination system: Evidence from software services offshoring. Organization Science; 25(4):1253-71 (2014).

50. Bolici, F., Howison, J., Crowston, K.; Stigmergic coordination in FLOSS development teams: Integrating explicit and implicit mechanisms. Cognitive Systems Research; 38:14$22(2016)$.

51. Huang, R., Zmud, R.W., Price, R.L.: Influencing the effectiveness of IT governance practices through steering committees and communication policies. European Journal of Information Systems;19(3):288-302 (2010).

52. Prasad, A., Heales, J., Green, P.: A capabilities-based approach to obtaining a deeper understanding of information technology governance effectiveness: Evidence from IT steering committees. international Journal of Accounting information Systems;11(3):214-32 (2010).

53. Kellogg, K.C., Orlikowski, W.J., Yates, J.: Life in the trading zone: Structuring coordination across boundaries in postbureaucratic organizations. Organization Science; 17(1):2244 (2006).

54. Pawlowski, S.D., Robey, D.: Bridging user organizations: Knowledge brokering and the work of information technology professionals. MIS Quarterly: 645-72 (2006).

55. Tanriverdi, H.: Information technology relatedness, knowledge management capability, and performance of multibusiness firms. MIS Quarterly. 2005:311-34.

56. Alexander, E.R.: Interorganizational Coordination: Theory and Practice. Journal of Planning Literature; 7:328-43 (1993).

57. March, J.G., Simon, H.A.: Organizations. Wiley: Oxford, England; p. 34-111 (1958).

58. Mintzberg, H. Structure in fives: Designing effective organizations. Prentice-Hall (1993).

59. Melin, U., Axelsson, K.: Understanding Organizational Coordination and Information Systems-Mintzberg's Coordination Mechanisms Revisited and Evaluated. European Conference on Information Systems Proceedings (2005).

60. Myers, M.D.: Qualitative research in information systems. Management information systems quarterly; 21 (1997).

61. Myers, M.D., Avison, D.E.: Qualitative Research in Information Systems: A Reader. Sage (2002).

62. Walsham, G.: Interpreting Information Systems in Organizations. Organization Studies;15 (1993).

63. Klein, H.K., Myers, M.D.: A Set of Principles for Conducting and Evaluating Interpretive Field Studies in Information Systems. MIS Quarterly; 23(1):67-93 (1999).

64. Goles, T., Hirschheim, R.: The paradigm is dead, the paradigm is dead...long live the paradigm: the legacy of Burrell and Morgan. Omega; 28(3):249-68 (2000).

65. Goldkuhl, G.: Pragmatism vs interpretivism in qualitative information systems research. European Journal of Information Systems; 21(2):135-46 (2012).

66. Cole, R,, Purao, S, Rossi, M., Sein, M.K.: Being Proactive: Where Action Research meets Design Research. ICIS 2005 Proceedings:1-21 (2005).

67. Mårtensson, P., Lee, A.S.: Dialogical action research at omega corporation. MIS Quarterly: 507-36 (2004).

68. Wilde, T., Hess, T.: Forschungsmethoden der Wirtschaftsinformatik Eine empirische Untersuchung. Wirtschaftsinformatik; 49(4):280-7 (2007). 
69. Boell, S., Cecez-Kecmanovic, D.: A Hermeneutic Approach for Conducting Literature Reviews and Literature Searches. Communications of the Association for Information Systems; 34(1):257-86 (2014).

70. Kotlarsky, J., Scarbrough, H., Oshri, I.: Coordinating expertise across knowledge boundaries in offshore-outsourcing projects: The role of codification. MIS Quarterly; 38(2):60727 (2014).

71. Simon, H.A.: The Sciences of the Artificial. Cambridge, MA (1969).

72. Van De Ven, A.H., Delbecq, A.L., Koenig, Jr. R.: Determinants of Coordination Modes within Organizations. American sociological review; 41(2):322-38 (1976).

73. Schelling, T.C.: The strategy of conflict. Harvard university press (1980).

74. Star, S.L., Griesemer, J.R.: Institutional Ecology, 'Translations' and Boundary Objects: Amateurs and Professionals in Berkeley's Museum of Vertebrate Zoology. Social Studies of Science; 19(3):387-420 (1989).

75. Henningsson, S., Rukanova, B., Hrastinski, S.: Resource dependencies in socio-technical information systems design research. Communications of the AIS; 27(42):777-802 (2010).

76. Clark HH. Using Language, Cambridge University Press (1996).

77. Reich, B.H., Benbasat, I.: Factors that influence the social dimension of alignment between business and information technology objectives. MIS Quarterly; 81-113 (2000).

78. Kuldeep, K., van Dissel, H.G.; Sustainable Collaboration: Managing Conflict and Cooperation in Interorganizational Systems. MIS Quarterly ;20:279-300 (1996).

79. Pfeffer, J., Salancik, G.R.: The External Control of Organizations: A Resource Dependence Perspective. Harper \& Row: New York (1978).

80. Gregor, S. The nature of theory in information systems. MIS Quarterly (2006). 